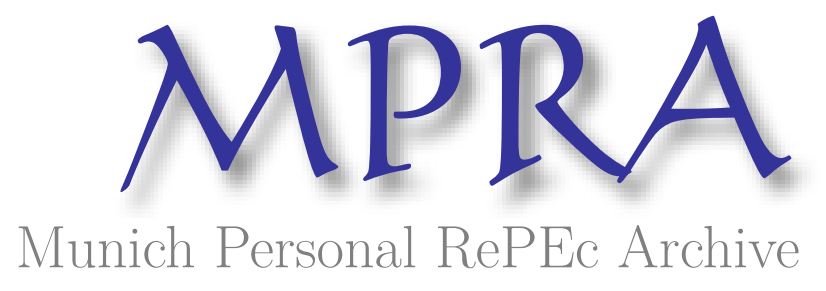

\title{
Population growth and industrialization
}

Zhou, Haiwen

13 January 2019

Online at https://mpra.ub.uni-muenchen.de/91449/

MPRA Paper No. 91449, posted 16 Jan 2019 14:42 UTC 


\title{
POPULATION GROWTH AND INDUSTRIALIZATION
}

\author{
Haiwen Zhou $^{1}$
}

Abstract

This paper formalizes Rostow's insight of the role of a leading sector in industrialization in a general equilibrium model. Population growth may lead to a shortage of food and a breakdown of the industrialization process. However, population growth may benefit the manufacturing sector in the adoption of increasing returns to scale technologies. Elasticity of demand for agricultural goods plays an important role in determining whether an improvement of agricultural technology or an increase of population is beneficial to the manufacturing sector. A comparison of China and Britain before the Industrial Revolution shows that R\&D is necessary for sustained growth. Achieving industrialization independently requires a combination of a sufficient market size from the demand side and a sufficient supply of technologies from the supply side. (JEL O14, E10, N10, Q01)

Keywords: Population growth, increasing returns to scale, industrialization, leading sector, Malthus population cycle

\section{INTRODUCTION}

What are the impacts of population growth on a country's possibility of achieving industrialization? On the one hand, if population growth always leads to higher economic activities, why did China before 1840 , the country with the largest population in the world at that time, could not achieve industrialization before Britain? A larger population may harm a country's ability to achieve industrialization as it may lead to a shortage of food. Thomas Malthus is a famous example of scholars with pessimistic views about the impact of population growth on industrialization. He assumes that population grows at an exponential rate, as also assumed in this paper. The production of food grows at a geometric rate. Compared to the growth rate of population, the growth rate of food is too small. If birth control is not implemented, food shortages might lead to famine and war. On the other hand, in the literature, it is also recognized that a larger population may be beneficial for industrialization since it makes the adoption of increasing returns to scale technologies more profitable. For example, North and Thomas (1973) and Rosenberg and Birdzell (1986) have shown that population growth and the development of commerce and trade preceded the Industrial Revolution in Europe. Ashton (1997, p.2) argues that "the outstanding feature of the social history of the period-the thing that above all others distinguishes the age (1760-

\footnotetext{
${ }^{1}$ This paper grew out of my undergraduate thesis at the Nankai University. I thank Ingrid Bryan, Mingchao Chen, Mark Lovewell, R. Preston McAfee, Robert Schwab, Daniel Vincent, Lei Wen, Lisheng Zhang, and anonymous referees for their insightful comments. The usual disclaimer applies.
} 
1830) from its predecessors-is the rapid growth of population. ${ }^{2}$ Thus, population growth may lead to Malthus population cycles in China and Europe before the arrival of the Industrial Revolution. However, population growth and development of commerce were beneficial for the Industrial Revolution in Britain.

This paper studies the role of population growth in the process of industrialization in a general equilibrium model. In each period, a representative individual consumes both agricultural and manufactured goods. Agricultural output is produced by land and labor by employing a constant returns to scale technology. The slow progress of the productivity of the agricultural sector may lead to a breakdown of the industrialization process, as the subsistence constraint requires that each individual needs a minimum level of agricultural goods to survive. We provide a formal presentation of the idea that the manufacturing sector is the leading sector of industrialization, as described by Rostow (1960): the effective amount of land may be augmented by agricultural technology, which is positively related to growth in the manufacturing sector. ${ }^{3}$ Manufactured goods may be produced by either a constant returns to scale technology or increasing returns to scale technologies (Murphy et al., 1989b). Increasing returns to scale come from fixed costs of production.

At early stages of development, the quantity of manufactured goods is too small to support the adoption of increasing returns to scale technologies. When the population grows large enough, increasing returns to scale technologies may be adopted. This starts the "take-off" process. If the improvement of agricultural technology is not great enough, population growth outpaces the growth of agricultural output. This gradually causes per capita consumption of agricultural goods to be lower than the subsistence level, leading to a breakdown of the growth process. In this sense, agriculture is the bottleneck of industrialization. However, if the manufacturing sector adopts new technologies fast enough and the spillover to the agricultural sector is large enough, an economy is able to escape the Malthus trap. Thus, sustained development is possible, as pioneered by Britain.

An interesting question is why Britain rather than China became the first country to achieve industrialization. Scholars such as Needham (1969), Lin (1995), and Pomeranz (2000) have tried

\footnotetext{
${ }^{2}$ Maddison (1982) records that population growth accompanies the process of industrialization.

${ }^{3}$ Rostow (1960, p. 53) illustrates the meaning of the leading sector as he writes "at any period of time it appears to be true even in a mature and growing economy that forward momentum is maintained as the result of rapid expansion in a limited number of primary sectors, whose expansion has significant external economy and other secondary effects."
} 
to understand the puzzle that ancient China achieved higher living standards not exceeded by any other country until the eighteen century, but it was unable to escape the Malthus trap. We present an extension of the model in which technological progress is a result of R\&D spending. ${ }^{4}$ Depending on the number of individuals employed in the R\&D sector, long run growth rate may be either zero or positive.

During the time period of British Industrial Revolution, talented individuals in China were spending time in preparing examinations to become government officials rather than engaging in R\&D. Without enough research input, lack of technical progress was inevitable in the Ming Dynasty (1369-1644) and Qing Dynasty (1644-1911) in China. As discussed in Pomeranz (2000), technical progress and temporary relief of land constraint through trade with the New World made it possible for Britain to escape the Malthus trap and achieved sustained growth. Overall, achieving industrialization independently requires a combination of a sufficient market size from the demand side and a sufficient supply of technologies from the supply side.

In the literature, Goodfriend and McDermott (1995) have examined the importance of population growth and the size of the market in the process of economic development. Tamura $(2002,2006)$ and Hansen and Prescott (2002) have studied market integration and transition from a traditional economy to a modern economy. Keller and Shiue (2007) and Shiue and Keller (2007) have conducted empirical research on market integration and economic development. This paper contributes to the literature by showing that population growth is a double-edged sword: it may provide a greater number of workers and a larger market for the manufacturing sector, but it may also strain the agricultural sector. A higher population does not necessarily lead to a larger market for manufactured goods. The reason is that with diminishing marginal returns to labor in the agricultural sector, a larger percentage of labor may need to work in the agricultural sector to produce sufficient amount of food for a larger population to survive.

This paper focuses on a closed economy as it studies a country's ability to achieve industrialization independently. In this paper, an improvement of agricultural technology may attract workers out of the manufacturing sector since a better agricultural technology increases the marginal productivity of agricultural workers. The importance of foreign trade in the industrialization process of Britain has been illustrated splendidly in Pomeranz (2000). Impact of

\footnotetext{
${ }^{4}$ In the literature, sustained growth may also be generated by human capital accumulation, as studied in Lucas (1988) and Tamura (1996a, 1996b).
} 
international trade with the existence of increasing returns to scale in the manufacturing sector has been studied by Zhou (2007a, 2007b). For a country trying to industrialize, the opening of trade may lead to two possibilities. The opening of international trade may make the subsistence constraint less likely to bind as agricultural goods may be imported, as the British case. However, if this country could not develop comparative advantage in the manufacturing sector, the opening of trade may lock the country into the production of agricultural goods. If a country's agricultural sector can benefit from technical progress in the manufacturing sector from other countries, specialization in the agricultural sector will not lead to a lower welfare for this country even in the long run. If technological spillovers are mainly within national borders, welfare implications for a country specializing in the agricultural sector will be more complicated.

The rest of the paper is organized as follows. Section II motivates the model by presenting historical evidence of the existence of Malthus cycles in China and Europe before the Industrial Revolution. Section III specifies the model. Section IV studies the equilibrium with the manufacturing sector employing a constant returns to scale technology. Section V conducts comparative statics on the equilibrium in which increasing returns to scale technologies are adopted in the manufacturing sector. Section VI provides an example of sustained growth in which the percentage of agricultural workers shrinks during the growth process. Section VII presents a growth path with endogenous technological progress. Section VIII discusses the differences between China and Britain before the Industrial Revolution. Section IX concludes.

\section{MALTHUS CYCLES IN ANCIENT CHINA AND EUROPE}

In this section, by presenting data on China's population cycles before 1840 and showing that the peak of economic activities was reached at the early stages of dynasties, we show the existence of Malthus population cycles in China before 1840.

Figure 1 presents official data and estimates of ancient China's population from Chao (1986, p. 41). ${ }^{5}$ He argues that "The cyclical movements (of population) are clearly visible." In China before 1840, at the beginning of a dynasty, compared to the amount of land available, the population was low due to past wars. Population increased in the peace times, which led to higher level of economic activities. When the population kept on increasing, agricultural technologies might not improve enough to provide enough food (Chao, 1986). Without enough food supplied

\footnotetext{
${ }^{5}$ Chao's data is based on Durand (1960), which contains a detailed discussion of the evolution of Chinese population.
} 
for the much larger population, large-scale famine might lead to rebellion of the poor. ${ }^{6}$ A large percentage of the population might be destroyed during the resulting wars. ${ }^{7}$ After dozens or even hundreds of years of social unrest, a new dynasty was established, and a new Malthus population cycle began.

FIGURE 1: Data of China's population, A. D. 2-A. D. 1776 (million)

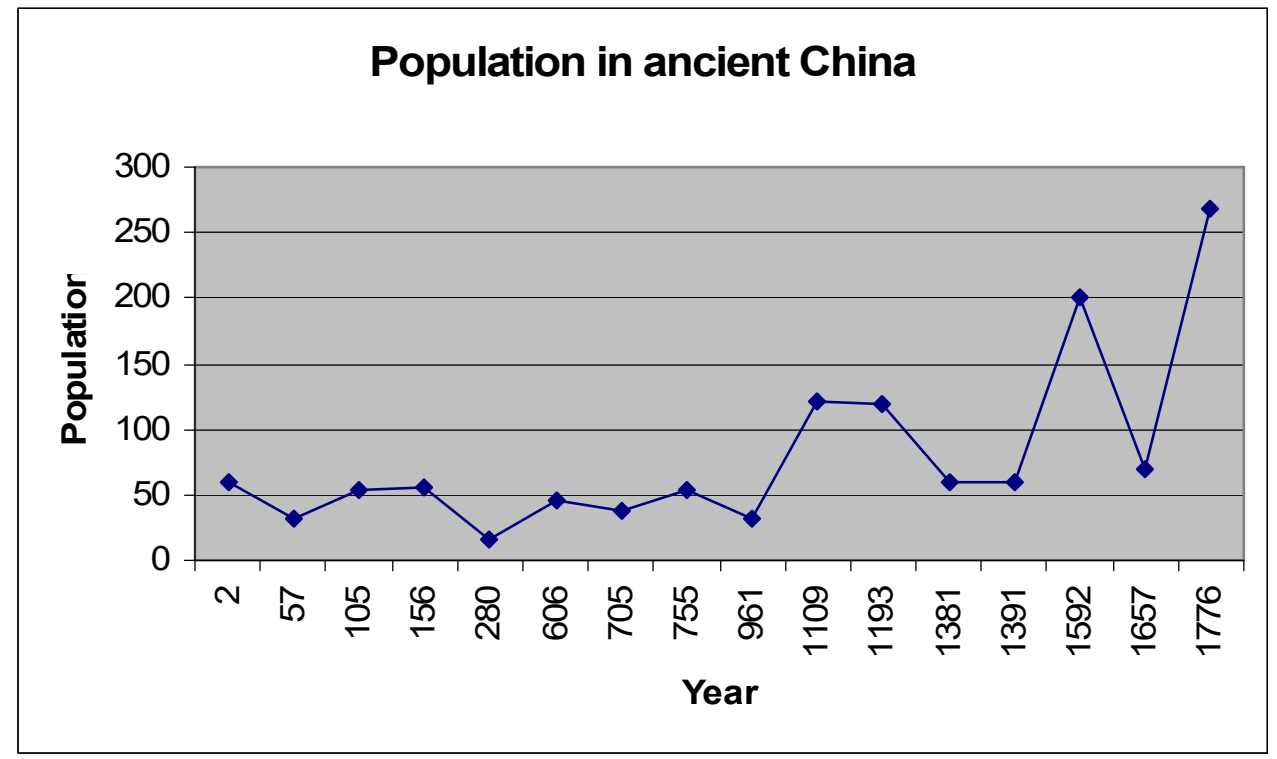

There were three well-known golden ages in China before 1840. All of the three golden ages happened at the early stages rather than at the ends of dynasties. First, the Rule of Wen and Jing of the Western Han Dynasty (206 BC-9) started in 180 BC and ended in 141 BC. Second, the Rule of Zhenguan of the Tang Dynasty (618-907) started in 626 and ended in 649 and Kaiyuan era started in 712 and ended in 741. Third, the Kang-Qian era of the Qing Dynasty (1644-1911) started in 1662 and ended in 1795.

Before the arrival of the Industrial Revolution, Malthus population cycles also existed in Europe. ${ }^{8}$ Figure 1 of Hansen and Prescott (2002, p.1207) shows the evolution of population and real wage rate for the English economy from 1275 to 1800 . Hansen and Prescott state that "the

\footnotetext{
${ }^{6}$ In China before 1840, when population grew, higher levels of economic activities increased the demand for money. With the usage of metals as money, money supply could not be easily adjusted to satisfy the increased demand. Thus, population cycles were frequently accompanied by monetary crises.

${ }^{7}$ First, disaster relief in 18th and 19th Century China is studied in Shiue (2004). Second, in China before 1840, largescale wars were also caused by other reasons, such as invasion.

${ }^{8}$ Part 1 of McEvedy and Jones (1978) has a discussion of the evolution of population in Europe.
} 
behavior of the English economy from the second half of the $13^{\text {th }}$ century until nearly 1800 is described well by the Malthusian model." Based on the above discussion of the evolution of population in China and Britain before the Industrial Revolution, it is important for a model addressing long run growth to accommodate the existence of Malthus population cycles.

\section{MODEL SPECIFICATION}

In this section, we set up the model. Time is continuous. Sometimes time indexes of variables are suppressed if there is no confusion from doing this. Each consumer or worker lives forever. Population grows at an exogenously given rate $\alpha$ : for $L_{0}$ denoting the starting population, population at time $t$ is given by $L_{t}=L_{0} e^{\alpha t}$. The motivation of an exogenous population growth rate is that human beings' control over birth was limited before the development of modern medical technologies. Historic records show that birth rates decreased only after countries had already achieved industrialization. In the case of China, Chao (1986, pp. 26-27) writes, "Newly available historical data strongly indicate that, at least in traditional China, population growth was an independent and exogenous variable in which the people responded by adjusting their production technologies and economic institutions."

There are two types of goods: agricultural goods and manufactured goods. Agricultural output is produced by land and labor. The supply of land is exogenously given and is normalized to one. However, the effective amount of land may be augmented by the agricultural technology: for $A_{t}$ denoting the level of agricultural technology at time $t$, the effective amount of land is $A_{t}$. Each worker has an equal ownership of land. For $\mu \in(0,1)$, the production function for the agricultural sector is of the Cobb-Douglas type: $G\left(A_{t}, L_{t}^{A}\right)=\left(A_{t}\right)^{1-\mu}\left(L_{t}^{A}\right)^{\mu}$, where $L_{t}^{A}$ is the amount of workers employed in the agricultural sector. From this specification, the agricultural production function exhibits constant returns to scale. For a given level of land, the marginal productivity of labor decreases.

A consumer's consumption of agricultural goods in period $t$ is $C_{t}^{A}$. There is a continuum of manufactured goods indexed by a number $\omega \in[0,1]$. A consumer's consumption of product $\omega$ is $C_{t}^{M}(\omega)$. It is assumed that all manufactured goods enter into a consumer's utility function symmetrically and a consumer's utility is separable over time. A consumer's utility in period $t$ is 
specified as $U_{t}=U\left(C_{t}^{A}, \int_{0}^{1} C_{t}^{M}(\omega) d \omega\right)$. Let $U_{A}$ denote the derivative of the utility function with respect to the agricultural goods if it exists. It is assumed that $U_{A} \geq 0, U_{A A} \leq 0$, and $U_{A M}=0$. Let $U_{M}$ denote the derivative of the utility function with respect to a manufactured good. It is assumed that $U_{M}>0$ and $U_{M M}<0$. In the following, we focus on symmetric equilibria. In a symmetric equilibrium, prices of all manufactured goods are the same and a consumer purchases equal amount of all the manufactured goods. As the total measure of the number of manufactured goods is one, we use $C_{t}^{M}$ to denote $\int_{0}^{1} C_{t}^{M}(\omega) d \omega$. The elasticity of demand for agricultural goods is defined as $\varepsilon_{t}^{A}=-U_{A} /\left(C_{t}^{A} U_{A A}\right)$ and the elasticity of demand for manufactured goods is defined as $\varepsilon_{t}^{M}=-U_{M} /\left(C_{t}^{M} U_{M M}\right)$

An important assumption in this paper is that the per capita consumption of agricultural goods cannot be lower than a critical level. The motivation of this assumption is that each individual needs a minimum level of food to survive. This constraint represents the land constraint. As discussed in Pomeranz (2000), land is needed to produce food, clothing, fuel, and wood for housing and construction. Let $\gamma$ denote this subsistence level of consumption of agricultural goods. The subsistence constraint is not binding at the starting time: $A_{0}{ }^{1-\mu} L_{0}{ }^{\mu} / L_{0} \geq \gamma$. As consumers are identical, a consumer's equilibrium level of consumption of agricultural goods equals total agricultural output divided by the total population, or $G\left(A_{t}, L_{t}^{A}\right) / L_{t}$. The subsistence constraint requires that $G\left(A_{t}, L_{t}^{A}\right) / L_{t} \geq \gamma$.

In this paper, the manufacturing sector plays the role of the leading sector in the process of industrialization. As discussed in Mokyr (1990, Chapter 6), there are many channels through which an increase in the productivity of the manufacturing sector may improve the productivity of the agricultural sector. First, improved manufacturing technologies may make some previously unusable land usable. Second, the development of the manufacturing sector provides better inputs for the agricultural sector, such as better seed and better fertilizer. Third, an improved manufacturing sector provides improved storage and transportation methods for the agricultural sector. Finally, some manufacturing technologies may be directly applicable in the agricultural sector. To capture the idea that growth in the manufacturing sector directly or indirectly improves the productivity of the agricultural sector, we assume that the technology of the agricultural sector 
is a continuous non-decreasing function of the cumulative output of the manufacturing sector. ${ }^{9}$ With this assumption, $A_{t}$ can be interpreted as the agricultural sector's "absorption capacity" of the spillovers from the manufacturing sector. The agricultural sector does not need to pay for this spillover. For $Q_{t}$ denoting the level of cumulative manufacturing output, $A_{t}=A_{t}\left(A_{0}, Q_{t}\right)$, and $d A_{t} / d Q_{t} \geq 0$.

To produce a manufactured product, either a constant returns to scale technology or increasing returns to scale technologies may be used. ${ }^{10}$ For the constant returns to scale technology, $b$ units of labor input are required to produce one unit of manufactured output, where $b$ is a positive constant. For the set of increasing returns to scale technologies, both a fixed cost and a marginal cost are needed. We assume that there is a continuum of increasing returns to scale technologies, indexed by $n$. A higher value of $n$ means a more advanced technology. In Sections $\mathrm{V}$ and VI, a firm's fixed cost of production measured in the units of labor used is $f(n)$. In Section VII, the fixed cost $f(n)$ comes from the purchase of machines. This firm's constant marginal cost of production measured in the units of labor used is $\beta(n)$. Similar to Zhou (2004, 2007a, 2007c), it is assumed that $f^{\prime}>0$ and $\beta^{\prime}<0$. That is, as a firm adopts a more advanced technology, the fixed cost of producing each good goes up, but the marginal cost of production goes down. This is the basic tradeoff faced by a firm in choosing its technology. For this set of technologies, there is a technology with the lowest fixed cost. Let this level of fixed cost be $f_{T}, T$ for take-off. The corresponding marginal cost for this technology is $\beta_{T}$. From the assumptions on costs, $\beta_{T}$ is the highest marginal cost for the set of increasing returns to scale technologies. It is assumed that $\beta_{T}<b$ : the marginal cost of production for an increasing returns to scale technology is always lower than that for the constant returns to scale technology.

\section{THE EQUILIBRIUM WITH CONSTANT RETURNS TO SCALE MANUFACTURING TECHNOLOGY}

At early stages of a civilization, the quantity of manufactured goods might be too small to support the adoption of increasing returns to scale technologies. Thus, the constant returns to scale

\footnotetext{
${ }^{9}$ The assumption that marginal cost decreases with accumulative output is similar to learning by doing.

${ }^{10}$ In Hansen and Prescott (2002), specialization is allowed so that a proportion of the economy uses the better technology and another proportion uses the old technology.
} 
technology is used in the manufacturing sector. This section studies a general equilibrium with the manufacturing sector employing the constant returns to scale technology.

The price of agricultural goods is $p_{t}^{A}$ and the price of manufactured goods is $p_{t}^{M}$. The wage rate in the manufacturing sector is $w$. Zero profit for a manufacturing firm leads to

$$
p_{t}^{M}-b w_{t}=0
$$

As all consumers are identical and there is no accumulation of physical capital, maximizing lifetime utility means maximizing utility each period. A consumer's income is the sum of the wage and the revenue from owning land. Because the revenue from owning land is $\left(p_{t}^{A} G-w_{t} L_{t}^{A}\right) / L_{t}$, a consumer's total income is $w_{t}+\frac{p_{t}^{A} G-w_{t} L_{t}^{A}}{L_{t}}$. A consumer's budget constraint in a period states that this consumer's total spending on agricultural and manufactured goods equals total income:

$$
p_{t}^{A} C_{t}^{A}+\int_{0}^{1} p_{t}^{M}(\omega) C_{t}^{M}(\omega) d \omega=w_{t}+\frac{p_{t}^{A} G-w_{t} L_{t}^{A}}{L_{t}}
$$

If the utility function is differentiable at the neighborhood of utility maximization, utility maximization leads to

$$
\frac{U_{A}\left(C_{t}^{A}\right)}{p_{t}^{A}}=\frac{U_{M}\left(C_{t}^{M}\right)}{p_{t}^{M}} .
$$

Labor demand is the sum of demand from the agricultural sector and the manufacturing sector. Labor demand from the agricultural sector is $L_{t}^{A}$. The total demand for labor from the manufacturing sector is $b X_{t}^{M}$ when total output in the manufacturing sector is $X_{t}^{M}$. As a worker has no preferences for leisure, each worker supplies one unit of labor inelastically. Thus, the total supply for labor is $L_{t}$. Labor market equilibrium requires that demand equals supply:

$$
L_{t}^{A}+b X_{t}^{M}=L_{t} .
$$

Each consumer demands $C_{t}^{A}$ units of agricultural goods and the total demand for agricultural goods is $L_{t} C_{t}^{A}$. The total supply of agricultural goods is $G\left(A_{t}, L_{t}^{A}\right)$. Clearance of market for agricultural goods requires that demand equals supply:

$$
L_{t} C_{t}^{A}=G\left(A_{t}, L_{t}^{A}\right) \text {. }
$$

Clearance of market for manufactured goods requires that 


$$
L_{t} C_{t}^{M}=X_{t}^{M}
$$

The agricultural sector is a perfectly competitive sector and the payment to a factor is its marginal product. Thus, the payment to a worker in the agricultural sector is $p_{t}^{A} d G / d L_{t}^{A}$. A worker receives $w$ in the manufacturing sector. Since a worker is able to move freely between the agricultural sector and the manufacturing sector, return in the two sectors should be equal:

$$
p_{t}^{A} \frac{d G}{d L_{t}^{A}}=w_{t} .
$$

In each period, equations (1)-(7) form a system of seven equations defining seven variables $p_{t}^{M}, p_{t}^{A}, C_{t}^{M}, C_{t}^{A}, L_{t}^{A}, X_{t}^{M}$, and $w$. The evolution of the economy is as follows. Population grows over time. As the accumulation of manufactured goods goes on, the agricultural technology may change over time. Since agricultural technology is determined by the accumulation of past manufactured output, it is exogenous in each period. As population and agricultural technology change over time, they drive other variables to evolve over time.

Throughout this paper, the wage rate is used as the numeraire: $w_{t} \equiv 1$. Interestingly, the system of equations (1)-(7) can be simplified to the following single equation defining $X_{t}^{M}$ :

$$
J \equiv b \mu\left(\frac{A_{t}}{L_{t}-b X_{t}^{M}}\right)^{1-\mu} U_{A}-U_{M}=0 .^{11}
$$

In equation (8), the arguments of $U_{A}$ and $U_{M}$ are $C_{t}^{A}$ and $C_{t}^{M}$. Since $C_{t}^{A}$ is equal to $A_{t}^{1-\mu}\left(L_{t}-b X_{t}^{M}\right)^{\mu} / L_{t}$ and $C_{t}^{M}$ is equal to $X_{t}^{M} / L_{t}$, equation (8) defines $X_{t}^{M}$ as a function of $L_{t}$ and $A_{t}$.

If agricultural technology improves, will it always benefit the manufacturing sector in the sense that the output of the manufacturing sector increases? The following proposition shows how the quantity of manufactured output changes with agricultural technology depends on whether the elasticity of agricultural goods is less than one or not.

PROPOSITION 1: A necessary and sufficient condition for $d X_{t}^{M} / d A_{t}>0$ is that $\varepsilon_{t}^{A}<1$.

\footnotetext{
${ }^{11}$ Equation (8) is derived by plugging the value of $p_{t}^{M}$ from (1), the value of $C_{t}^{A}$ from (5), the value of $C_{t}^{M}$ from (6), and the value of $p_{t}^{A}$ from (7) into equation (3).
} 


$$
\begin{gathered}
\text { Proof: From (8), } \frac{d X_{t}^{M}}{d A_{t}}=-\frac{\partial J / \partial A_{t}}{\partial J / \partial X_{t}^{M}} \cdot \text { Also from (8), } \frac{\partial J}{\partial A_{t}} \\
=(1-\mu) b \mu A_{t}^{-\mu}\left(L_{t}-b X_{t}^{M}\right)^{\mu-1}\left(U_{A}+C_{t}^{M} U_{A A}\right) \text {. Thus, } d X_{t}^{M} / d A_{t}>0 \text { if and only if } \varepsilon_{t}^{A}<1 .
\end{gathered}
$$

The intuition behind Proposition 1 is as follows. Since the agricultural technology is CobbDouglas, wage payment to agricultural workers is a fixed percentage of agricultural revenue. Thus, there is a direct relationship between the number of workers employed in the agricultural sector and agricultural revenue. Other things equal, an improvement of agricultural technology leads to an increase of agricultural output. When the elasticity is lower than one, an output increase leads to a decrease of agricultural revenue. This leads to workers moving out of the agricultural sector and an increase of manufactured output because the manufactured output is directly related to the number of workers in the manufacturing sector. It is commonly believed that elasticity of demand for agricultural goods is lower than one. ${ }^{12}$ Thus, Proposition 1 provides a qualification for the importance of agricultural efficiency in industrialization. ${ }^{13}$

As a higher level of manufactured output makes the adoption of increasing returns to scale technology in the manufacturing sector more likely, one interesting question is whether a higher population always leads to a higher level of manufactured output. This may not be true, because adding one more person increases the demand for agricultural goods and the agricultural sector has diminishing returns to labor. The following proposition shows that a sufficient condition for the quantity of manufacturing output to increase with the population is that the elasticity of agricultural goods is less than one.

PROPOSITION 2: If $\varepsilon_{t}^{A}<1, \frac{d X_{t}^{M}}{d L_{t}}>0$.

Proof: see the Appendix.

\footnotetext{
${ }^{12}$ Suits $(2005$, p. 4) presents a table of elasticity of demand for selected farm products. The absolute value of the elasticity of demand for potato is 0.27 and for corn is 0.63 . However, for some luxury agricultural goods the elasticity can be higher than one. For example, the elasticity of fresh peas is 2.83 .

${ }^{13}$ For example, Rostow's (1960, p. 8) argues that "the revolutionary changes in agricultural productivity are an essential condition for successful take-off; for modernization of a society increases radically its bill for agricultural products."
} 
A comparison of Propositions 1 and 2 reveals that an increase of population is more likely to increase manufactured output than an improvement of agricultural technology. The reason is that an improvement of agricultural technology leads to an increase of marginal productivity of agricultural workers. Other things equal, this will attract more workers into the agricultural sector.

\section{ADOPTION OF INCREASING RETURNS TO SCALE TECHNOLOGIES AND INDUSTRIALIZATION}

In this section, the equilibrium with increasing returns to scale in the manufacturing sector is studied. Whether growth is sustainable or not so that industrialization can be achieved is discussed. For growth to be sustainable, the per capita consumption of both types of goods after take-off should not decrease over time and the subsistence constraint should never bind.

If total manufactured output is large enough, a firm using increasing returns to scale technology will emerge. Let $X_{T}$ denote this level of total manufactured output. The time that an increasing returns to scale technology is adopted in the manufacturing sector can be viewed as the point of take-off. If $f\left(b-\beta_{T}\right) \geq f_{T}(b-\beta)$, when an increasing returns to scale technology is adopted, the technology with the lowest level of fixed cost will be adopted first. ${ }^{14}$ With this technology, the average units of labor needed to produce a unit of manufacturing goods are $\left(f_{T}+\beta_{T} X_{T}\right) / X_{T} \cdot{ }^{15}$ For the adoption of increasing returns to scale technology to be profitable, $\left(f_{T}+\beta_{T} X_{T}\right) / X_{T}$ should be smaller than or equal to $b$. Equalization of $\left(f_{T}+\beta_{T} X_{T}\right) / X_{T}$ and $b$ leads to $X_{T}=f_{T} /\left(b-\beta_{T}\right)$. From this equation, the minimum manufactured output needed for take-off increases with the fixed cost of production $\left(f_{T}\right)$ and decreases with the cost advantage of increasing returns to scale technology $\left(b-\beta_{T}\right)$.

All manufacturing firms have access to the set of increasing returns to scale technologies. Firms are allowed to freely enter or exit an industry. As the quantity of manufactured goods keeps on growing, new firms may enter the manufacturing sector. In equilibrium, each firm makes a profit of zero. ${ }^{16}$ Let $S$ denote the earliest time that increasing returns to scale technologies have

\footnotetext{
${ }^{14}$ The interpretation of $f\left(b-\beta_{T}\right) \geq f_{T}(b-\beta)$ is that the rate of increase of fixed costs is higher than the rate of decrease of marginal costs.

${ }^{15}$ At the beginning of the industrialization process, market size is large enough for only one firm adopting increasing returns technologies. When there is only one firm in the industry, firm level of output is equal to the industry level of output.

${ }^{16}$ To simplify the presentation, in this paper the number of firms is not required to be an integer number.
} 
been adopted and manufacturing firms are earning a profit of zero. For the rest of this section, we study the evolution of the economy that time $S$ has been reached.

When there are multiple firms producing the manufactured good, they are assumed to engage in Cournot competition. The number of firms producing the same product $m$ is determined by the zero-profit condition. As there is a continuum of manufactured goods, a firm takes the wage rate as given. Let $x$ denote a manufacturing firm's output when increasing returns to scale technologies are being used. A manufacturing firm's profit is $\Pi_{t} \equiv p_{t}^{M} x_{t}-\left(f\left(n_{t}\right)+\beta\left(n_{t}\right) x_{t}\right) w_{t}$. A manufacturing firm chooses its level of technology and its level of output to maximize its profit. A firm's optimal choice of the level of output leads to the following first order condition with respect to $x$ :

$$
p_{t}^{M}+x_{t} \frac{\partial p_{t}}{\partial x_{t}}-\beta_{t} w_{t}=0
$$

A firm's optimal choice of the level of technology leads to the following first order condition with respect to $n$ :

$$
f^{\prime}\left(n_{t}\right)+\beta^{\prime}\left(n_{t}\right) x_{t}=0 .{ }^{17}
$$

From a consumer's utility maximization, $\frac{\partial p_{t}^{M}}{\partial x_{t}}=-\frac{p_{t}^{M}}{m_{t} x_{t} \varepsilon_{t}^{M}}$. Combining this with equation (9) leads to the following equation showing that a firm's price is a markup over its marginal cost of production:

$$
p_{t}^{M}\left(1-\frac{1}{m_{t} \varepsilon_{t}^{M}}\right)=\beta_{t} w_{t}
$$

To simplify notation, in the following, $f$ is used to denote $f\left(n_{t}\right)$ and $\beta$ is used to denote $\beta\left(n_{t}\right)$. Total demand for labor is the sum of demand from the agricultural sector and the manufacturing sector. Labor demand from the agricultural sector is $L_{t}^{A}$. There are $m$ manufacturing firm each demands $f+\beta x$ units of labor. Thus, the total demand for labor from the manufacturing sector is $m(f+\beta x)$. The total supply of labor in a period is $L_{t}$. Clearance of labor market requires that demand equals supply:

\footnotetext{
${ }^{17}$ The second order condition requires that $f^{\prime \prime}\left(n_{t}\right)+\beta^{\prime \prime}\left(n_{t}\right) x_{t}>0$. It is assumed that this second order condition is satisfied. This second order condition is used later on to sign comparative static studies.
} 


$$
L_{t}^{A}+m_{t}\left(f+\beta x_{t}\right)=L_{t}
$$

The total demand for manufactured goods is $L_{t} C_{t}^{M}$. There are $m$ manufacturing firms and each firm supplies $x$ units of output. Thus, the total supply of manufactured goods is $m x$. Clearance of market for manufactured goods requires that demand equals supply:

$$
L_{t} C_{t}^{M}=m_{t} x_{t} .
$$

Zero profit of a manufacturing firm requires that

$$
p_{t}^{M} x_{t}-\left(f+\beta x_{t}\right) w_{t}=0 \text {. }
$$

The accumulation of manufactured output is

$$
Q_{t}=Q_{S}+\int_{S}^{t} m_{\tau} x_{\tau} d \tau, \text { for } t \geq S
$$

Equations (2), (3), (5), and (7) continue to hold when increasing returns to scale technologies are being used in the manufacturing sector. In each period, equations (2), (3), (5), (7), and (10)-(14) form a system of nine equations defining the nine variables $p_{t}^{M}, p_{t}^{A}, C_{t}^{M}, C_{t}^{A}$ , $L_{t}^{A}, m, x, n$, and $w$. Simplification of the above system of equations leads to

$$
\begin{aligned}
& V_{1} \equiv f^{\prime}\left(p_{t}^{M}-\beta\right)+\beta^{\prime} f=0, \\
& V_{2} \equiv \frac{1}{f \varepsilon_{t}^{M}}\left(\frac{f^{\prime} \beta-f \beta^{\prime}}{\beta^{\prime}}\right)^{2}-\left(L_{t}-L_{t}^{A}\right)=0, \\
& V_{3} \equiv \mu\left(f^{\prime} \beta-f \beta^{\prime}\right)\left(\frac{A_{t}}{L_{t}^{A}}\right)^{1-\mu} U_{A}-f^{\prime} U_{M}=0 .{ }^{18}
\end{aligned}
$$

In equation (16c), the arguments of $U_{A}$ and $U_{M}$ are $C_{t}^{A}$ and $C_{t}^{M}$. Since $C_{t}^{A}$ is equal to $A_{t}^{1-\mu}\left(L_{t}^{A}\right)^{\mu} / L_{t}$ and $C_{t}^{M}$ is equal to $\frac{\left(L_{t}-L_{t}^{A}\right) f^{\prime}}{\left(f^{\prime} \beta-f \beta^{\prime}\right) L_{t}}, U_{A}$ and $U_{M}$ are functions of $A_{t}, L_{t}^{A}$, and $n$. In each period, equations (16a)-(16c) define the three variables $L_{t}^{A}, n$, and $w$ as functions of $A_{t}$ and $L_{t}$.

\footnotetext{
${ }^{18}$ Equations (16a)-(16c) are derived as follows. First, (16a) is derived from (10) and (14). Second, (16b) is derived by plugging the value of $m_{t}$ from (11) and the value of $x_{t}$ from (14) into (12), and replacing $p_{t}^{M}$ by employing (16a). Third, (16c) is derived by plugging the value of $C_{t}^{A}$ from (5), the value of $C_{t}^{M}$ from (11), (13), and (14), and the value of $p_{t}^{A}$ from (7) into (3), and replacing $p_{t}^{M}$ by employing (16a).
} 
Total differentiation of equations (16a)-(16c) with respect to $p_{t}^{M}, L_{t}^{A}, n_{t}, A_{t}$, and $L_{t}$ leads to

$$
\left(\begin{array}{ccc}
\frac{\partial V_{1}}{\partial p_{t}^{M}} & 0 & \frac{\partial V_{1}}{\partial n_{t}} \\
0 & \frac{\partial V_{2}}{\partial L_{t}^{A}} & \frac{\partial V_{2}}{\partial n_{t}} \\
0 & \frac{\partial V_{3}}{\partial L_{t}^{A}} & \frac{\partial V_{3}}{\partial n_{t}}
\end{array}\right)\left(\begin{array}{l}
d p_{t}^{M} \\
d L_{t}^{A} \\
d n_{t}
\end{array}\right)=-\left(\begin{array}{c}
0 \\
0 \\
\frac{\partial V_{3}}{\partial A_{t}}
\end{array}\right) d A_{t}-\left(\begin{array}{c}
\frac{\partial V_{2}}{\partial L_{t}} \\
\frac{\partial V_{3}}{\partial L_{t}}
\end{array}\right) d L_{t}
$$

Let $\Delta$ denote the determinant of the coefficient matrix of (17). For stability, it is assumed that $\Delta<0$. From (16a), $\frac{\partial V_{1}}{\partial p_{t}^{M}}=f^{\prime}$. From (16b), $\frac{\partial V_{2}}{\partial L_{t}}=-1$, and $\frac{\partial V_{2}}{\partial L_{t}^{A}}=1$. Partial differentiation of (16c) yields

$$
\begin{aligned}
\frac{\partial V_{3}}{\partial L_{t}} & =-\mu\left(f^{\prime} \beta-f \beta^{\prime}\right)\left(\frac{A_{t}}{L_{t}^{A}}\right)^{1-\mu} \frac{A_{t}^{1-\mu}\left(L_{t}^{A}\right)^{\mu}}{L_{t}^{2}} U_{A A}-\frac{\left(f^{\prime}\right)^{2} L_{t}^{A}}{\left(f^{\prime} \beta-f \beta^{\prime}\right) L_{t}^{2}} U_{M M}>0, \\
\frac{\partial V_{3}}{\partial A_{t}} & =\mu(1-\mu)\left(f^{\prime} \beta-f \beta^{\prime}\right) A_{t}^{-\mu}\left(L_{t}^{A}\right)^{\mu-1}\left(U_{A}+C_{t}^{A} U_{A A}\right) . \\
\frac{\partial V_{3}}{\partial L_{A}^{t}} & =\mu\left(f^{\prime} \beta-f \beta^{\prime}\right) A_{t}^{1-\mu}\left(L_{t}^{A}\right)^{\mu-2}\left(\frac{\mu A_{t}^{1-\mu}\left(L_{t}^{A}\right)^{\mu}}{L_{t}} U_{A A}-(1-\mu) U_{A}\right) \\
& +\frac{\left(f^{\prime}\right)^{2}}{\left(f^{\prime} \beta-f \beta^{\prime}\right) L_{t}} U_{M M}<0 .
\end{aligned}
$$

The following proposition shows that an improvement of technology in the agricultural sector increases the real wage rate and helps the manufacturing sector to adopt a more advanced technology if and only if the elasticity of agricultural goods is lower than one.

PROPOSITION 3: A necessary and sufficient condition for $d p_{t}^{M} / d A_{t}<0$ and $d n_{t} / d A_{t}>0$ is that $\varepsilon_{t}^{A}<1$.

Proof: Application of Cramer's rule leads to

$$
\frac{d p_{t}^{M}}{d A_{t}}=\frac{\partial V_{1}}{\partial n_{t}} \frac{\partial V_{2}}{\partial L_{t}^{A}} \frac{\partial V_{3}}{\partial A_{t}} / \Delta
$$




$$
\frac{d n_{t}}{d A_{t}}=-\frac{\partial V_{1}}{\partial p_{t}^{M}} \frac{\partial V_{2}}{\partial L_{t}^{A}} \frac{\partial V_{3}}{\partial A_{t}} / \Delta
$$

By using the second order condition for a manufacturing firm's optimal choice of output, it can be shown that $\partial V_{1} / \partial n_{t}>0$. From (19), $d p_{t}^{M} / d A_{t}<0$ and $d n_{t} / d A_{t}>0$ if and only if $U_{A}+C_{t}^{A} U_{A A}>0$

Application of Cramer's rule leads to $\frac{d L_{t}^{A}}{d A_{t}}=\frac{\partial V_{1}}{\partial p_{t}^{M}} \frac{\partial V_{2}}{\partial n_{t}} \frac{\partial V_{3}}{\partial A_{t}} / \Delta$. From (19), the sign of $d L_{t}^{A} / d A_{t}$ is sensitive to the sign of $U_{A}+C_{t}^{A} U_{A A}$. However, the sign of $d L_{t}^{A} / d A_{t}$ cannot be determined since the sign of $\partial V_{2} / \partial n_{t}$ cannot be determined.

The intuition behind Proposition 3 is as follows. Other things equal, an improvement of technology in the agricultural sector increases the marginal productivity of agricultural workers. If the elasticity of demand for agricultural goods is lower than one, it is not profitable to charge a lower price to sell more agricultural output. This means that overall the payment to agricultural workers increases. As workers are free to move between sectors, return to workers in the manufacturing sector has to be increased. Since the wage rate is normalized to one, an increase of real wage is achieved through a decrease of the price of manufactured goods. As manufactured firms make a profit of zero, a lower price of manufactured goods is directly related to a more advanced technology since a more advanced technology decreases the average cost of production. The number of agricultural workers may not decrease as the number of manufacturing firms may also adjust. However, if $\partial V_{2} / \partial n_{t}>0$, the number of agricultural workers decreases.

Does a higher population lead to a more advanced technology to be adopted in the manufacturing sector? Proposition 4 shows that an inelastic elasticity of demand for agricultural goods is a sufficient condition for the manufacturing technology to increase with the population.

PROPOSITION 4: If $\varepsilon_{t}^{A}<1, d n_{t} / d L_{t}>0$.

Proof: see the Appendix.

The intuition behind Proposition 4 is as follows. As population grows, a manufacturing firm's quantity of production increases. This leads to more advanced technologies to be adopted 
because a more advanced technology leads to a lower average cost of production if output is large enough. As a result, the real wage rate measured in manufactured goods increases because a firm makes a profit of zero. So population growth leads to an increase of per capita consumption of manufactured goods.

In this model, in general, the potential constraint of industrialization is the agricultural sector. From (5), the evolution of per capita consumption of agricultural goods is given by $\frac{\dot{C_{t}^{A}}}{C_{t}^{A}}=(1-\mu) \frac{\dot{A}_{t}}{A_{t}}+\mu \frac{\dot{L_{t}^{A}}}{L_{t}^{A}}-\alpha$. Thus, for the growth rate of per capita consumption of agricultural goods to be positive, the sum of the growth rates of agricultural technology and individuals employed in the agricultural sector has to be larger than the population growth rate. Depending on the preferences, the specifications of the manufacturing technology and the agricultural technology, and the initial conditions, there are two cases. In the first case, if the change of technology in the agricultural sector is slow, with diminishing marginal productivity in the agricultural sector, more and more workers are employed in the agricultural sector. This decreases the number of workers available in the manufacturing sector. As the manufactured output decreases, this slows next period's increase of agricultural productivity. This vicious cycle eventually causes per capita consumption of agricultural goods to be lower than the critical level and an interruption of the industrialization process. In this case, agriculture is the bottleneck of industrialization. In the second case, if the change of agricultural technology is fast enough, the subsistence constraint never binds. In this case, a person's consumption of manufactured goods and agricultural goods increase over time.

\section{AN EXAMPLE OF INDUSTRIALIZATION WITH STRUCTURAL CHANGE}

In this section, by proceeding with special production costs and utility function, we provide an example in which sustained growth results. A typical phenomenon observed in the development process is the relocation of labor force from the agricultural sector to the manufacturing sector. This feature is captured in this example in which the percentage of agricultural workers declines

over time. The fixed and marginal costs are specified as $f(n)=n^{1 / 2}$, and $\beta(n)=n^{-1 / 2}$. A consumer's utility function is specified as $U_{t}=-\infty$, if $C_{t}^{A}<\gamma$, and $U_{t}=\ln \left(C_{t}^{M}\right)$, if $C_{t}^{A} \geq \gamma$. For this utility function, a consumer derives no utility from consuming more than the subsistence 
level of agricultural goods. This extreme assumption highlights the empirical regularity that the income elasticity of demand for agricultural goods is smaller than that for manufactured goods (Murphy et al., 1989a).

At the beginning of the adoption of increasing returns to scale technologies, the size of the market for manufactured goods is too small and only one manufacturing firm is viable for each manufactured product. This monopoly firm makes a nonnegative profit. As population grows, the size of the market for manufactured goods expands and more firms will enter. Eventually, each manufacturing firm makes a profit of zero. The economy evolves through three stages: before $T$, between $T$ and $S$, and after $S$. In all the three stages, per capita consumption of agricultural goods is constant at $\gamma$.

First, we examine the evolution of the economy before its takeoff. Solving the system of equations (1)-(7) yields

$$
\begin{aligned}
& X_{t}^{m}=\frac{1}{b}\left(L_{t}-\frac{\gamma L_{t}}{A_{t}^{1-\mu}}\right)^{1 / \mu}, \\
& C_{t}^{m}=\frac{1}{b}-\frac{1}{b L_{t}}\left(\frac{\gamma L_{t}}{A_{t}^{1-\mu}}\right)^{1 / \mu}
\end{aligned}
$$

The equilibrium number of agricultural workers is given by

$$
L_{t}^{A}=\left(\frac{\gamma L_{t}}{A_{t}^{1-\mu}}\right)^{1 / \mu}
$$

It can be checked that this relationship is also valid for the two other stages.

Second, we study the evolution of the economy from time $T$ to time $S$. The firm with increasing returns to scale technology will produce at an output level leading to a price slightly smaller than $b$ so that firms with constant returns to scale technology could not compete. Thus, all the manufactured output is produced by this firm. This firm still chooses its technology optimally. Since the manufacturing firm's profit $\Pi_{t}$ is distributed equally to all consumers, a consumer's budget constraint becomes

$$
p_{t}^{A} C_{t}^{A}+p_{t}^{M} C_{t}^{M}=w_{t}+\frac{p_{t}^{A} G-w_{t} L_{t}^{A}+\Pi_{t}}{L_{t}} .
$$

Labor market equilibrium requires that 


$$
L_{t}^{A}+f+\beta x_{t}=L_{t} .
$$

Market equilibrium for manufactured goods requires that

$$
L_{t} C_{t}^{M}=x_{t} .
$$

Equations (24)-(26) and equations (1), (5), (7), and (10) define the evolution of the economy between time $T$ to $S$. Solving this system of equations yields

$$
x_{t}=\frac{1}{4}\left(L_{t}-\left(\frac{\gamma L_{t}}{A_{t}^{1-\mu}}\right)^{1 / \mu}\right)^{2} .
$$

As population grows over time, new firms will enter the manufacturing sector and all manufacturing firms make a profit of zero. The economy thus evolves into the third stage.

Finally, we study the evolution of the economy after $S$. Solving the system of equations (2), (3), (5), (7), and (10)-(14) leads to

$$
\begin{aligned}
& m_{t}=2, \\
& x_{t}=\frac{1}{16}\left(L_{t}-\left(\frac{\gamma L_{t}}{A_{t}^{1-\mu}}\right)^{1 / \mu}\right)^{2}, \\
& C_{t}^{M}=\frac{1}{8 L_{t}}\left(L_{t}-\left(\frac{\gamma L_{t}}{A_{t}^{1-\mu}}\right)^{1 / \mu}\right)^{2} .
\end{aligned}
$$

In (28), this specific number of firms is a result of the special utility function. With a general utility function, the number of manufacturing firms depends on the elasticity of demand for manufactured goods: the lower the elasticity of demand, the higher the number of manufacturing firms producing the same product. The intuition behind this result is that a lower elasticity enables a firm to charge a higher markup over its marginal cost of production. Other things equal, this increases the number of firms producing the same product. From (29), the size of a manufacturing firm increases over time.

For $A_{0}{ }^{1-\mu}>\gamma$ and $A_{t}=A_{0} Q_{t} \frac{\mu}{1-\mu}$, this specification of agricultural technology is sufficient to generate rate sustained growth. This can be checked as follows. From (21), (27), (28), and (29), aggregate manufactured output grows at a rate not smaller than $\alpha / \mu$. Thus, agricultural technology improves at a rate not smaller than $\alpha /(1-\mu)$. From (23), the percentage of agricultural workers decreases over time. From (27) and (30), after takeoff, per capita consumption of 
manufactured goods increases over time. The intuition behind this specification of agricultural technology is that the initial agricultural technology should be large enough so that not all workers are absorbed into the agricultural sector at the beginning of the development process and later on agricultural technology has to increase at a rate faster enough to make up the decrease of the percentage of workers in the agricultural sector. Obviously, a better initial agricultural technology and a faster rate of improvement of technology in the agricultural sector will make sustained development more likely.

\section{ECONOMIC GROWTH WITH ENDOGENOUS TECHNICAL PROGRESS}

It is unlikely that the different growth paths in China and Britain before the Industrial Revolution were caused by differences in the elasticity of demand for agricultural products in the two countries. In this section, to facilitate the discussion of the differences between China and Europe before the Industrial Revolution in the next section, we study economic growth with endogenous technical progress.

Let $\tau$ denote a positive constant, a consumer tries to maximize utility $\int_{S}^{\infty} e^{-\rho t} U_{t} d t$, where $U_{t}=-\infty$, if $C_{t}^{A}<\gamma$; and $U_{t}=\log C_{t}^{A}+\tau \log C_{t}^{M}$, if $C_{t}^{A} \geq \gamma$. Similar to Romer (1990), new technologies have to be developed by costly R\&D effort. In addition to the agriculture and the manufacturing sector, there is a sector in which workers develop new designs. Designs are used to produce machines to be used by the manufacturing sector. A technology indexed by $n$ incorporates $n$ units of machines and the amount of labor needed for this technology is $1 / n$. That is, $f(n)=n$ and $\beta(n)=1 / n .{ }^{19}$

Let $\delta$ denote a positive constant. If $L_{n}$ is the amount of labor employed in the production of new designs, the evolution of new designs is specified as

$$
\dot{n}=\delta n \frac{L_{n}}{L}
$$

A worker's return in the manufacturing sector is $w$. From (31), one unit of labor is able to produce $\delta n / L_{t}$ units of design. For $p_{n}$ denoting the price of one unit of design, the return for

\footnotetext{
${ }^{19}$ As shown in List and Zhou (2007), this specification of technology is unnecessarily restrictive to generate sustained growth. More general specification of fixed and marginal costs can also generate the result that per capita consumption increases with the population.
} 
a worker engaging in producing designs is $\delta n p_{n} / L_{t}$. Depending on whether employment in the R\&D sector is profitable or not, there are two cases. In the first case, the return from employed in the R\&D sector is lower than that from employed in other sectors, there is no employment in the $\mathrm{R} \& \mathrm{D}$ sector and the long-run growth rate is zero. In the second case, there is employment in the R\&D sector and the growth rate is positive.

We now study the positive growth case. Since a worker may work in either the R\&D sector or the manufacturing sector, the return in these sectors should be equal: $w_{t}=\delta n p_{n} / L_{t}$. As a result, $p_{n}=w_{t} L_{t} /(\delta n)$. We focus on the evolution of the economy after time $S$ at that time increasing returns to scale technologies have already been adopted. Let $g$ denote the steady-state balanced growth rate whose value will be determined later on. For $A_{S}$ denoting the level of agricultural technology and $x_{S}$ denote the level of manufacturing output at time $S$, the relationship between agricultural technology and aggregate industry output is specified as $A_{t}=\left(\frac{\alpha+g}{2 x_{S}}\right)^{\alpha /(\alpha+g)} A_{S} Q_{t}^{\alpha /(\alpha+g)}, t>S$. Since $x_{S}$ and $A_{s}$ are determined at time $S$, the evolution of agricultural technology after $S$ is well defined. This specification of agricultural technology is chosen so that in the balanced growth path, per capita consumption of agricultural goods is constant. We will show that per capita consumption of manufactured goods increases at the constant balanced growth rate.

For $r$ denoting the interest rate, a consumer's utility maximization leads to

$$
\begin{aligned}
& \tau C_{t}^{A} p_{t}^{A}=C_{t}^{M} p_{t}^{M}, \\
& \frac{C_{t}^{M}}{C_{t}^{M}}=r-\rho-\frac{p_{t}^{M}}{p_{t}^{M}} .
\end{aligned}
$$

In a balanced growth path, the rate of consumption of manufactured goods increases at the same rate as the decrease of the price of manufactured goods. Equation (33) leads to

$$
r=\rho \text {. }
$$

That is, the interest rate is equal to the discount rate. Also, the interest rate is constant over time.

Once a new design is available, a piece of machine can be produced. The rental price of a piece of machine is $R$. We treat $R$ to be constant over time. For the growth path studied in this section, this treatment is valid as it is shown later on that $R$ is constant. For a firm producing 
machines, in each period it gets $R$ from each of the $m$ firms and its revenue is $m R$ in each period. Thus, its total discounted revenue is $m R / r$. Its cost comes from buying the design which is equal to $p_{n}$. Free entry into the R\&D sector leads to zero profit for a firm producing machines: $\frac{m R}{r}-p_{n}=0$.

A manufacturing firm's fixed cost comes from the purchase of machines. Thus, a manufacturing firm's profit is $p_{t}^{M} x_{t}-n R-\beta \times w$. A manufacturing firm makes a profit of zero: $p_{t}^{M} x_{t}-n R-\beta x w=0$. Optimal choice of technology by a manufacturing firm leads to $R+\beta_{t}{ }^{\prime} x_{t} w=0$. Since $\beta(n)=1 / n$, this leads to $n R=w x_{t} / n$. Combination of this with the result that a firm producing manufactured goods has a profit of zero, we get

$$
p_{t}^{M} x_{t}=2 n R \text {. }
$$

Combination of the zero-profit condition for a manufacturing firm with $f(n)=n$ yields

$$
R=\frac{\left(p_{t}^{M}-\beta_{t} w\right) x_{t}}{f}=\frac{1}{n\left(m_{t}-1\right)} \beta_{t} w_{t} x_{t} .
$$

We now derive the number of manufacturing firms producing the same product. Plugging the value of $R$ from (36) into (35) leads to $p_{t}^{M}=\frac{2}{n\left(m_{t}-1\right)} w$. With the special utility function, the elasticity of demand for manufactured goods is equal to one, thus optimal choice of output leads to $p_{t}^{M}\left(1-\frac{1}{m_{t}}\right)=\beta_{t} w_{t}$. This leads to $p_{t}^{M}=\frac{m_{t}}{n\left(m_{t}-1\right)} w$. A comparison of the above two expressions for the price of manufactured goods reveals the number of manufacturing firms producing the same product is given by $m=2$.

The total supply of labor is $L_{t}$. The demand for labor is the sum of demand from the agricultural sector, demand for labor used in the production of new designs, and the manufacturing sector. Labor market equilibrium requires that $L_{t}^{A}+L_{n}+m_{t} \beta x=L_{t}$. Since $m=2$ and $p_{n}=w_{t} L_{t} /(\delta n)$, from this labor market equilibrium condition and the zero-profit condition for a firm producing machines, the interest rate can be expressed as

$$
r=\frac{\delta\left(L_{t}-L_{n}-L_{t}^{A}\right)}{L_{t}} .
$$


We now derive the number of individuals employed in the agricultural sector as a function of the total labor force. Equation (7) is still valid. The income of workers in the agricultural sector is $w_{t} L_{t}^{A}$. Since agricultural workers contribute a percentage of $\mu$ to the value of agricultural sector, the total value of the agriculture sector is $w_{t} L_{t}^{A} / \mu$. From (32), in each period, $1 /(1+\tau)$ percent of expenditure is spent on agricultural goods. In each period, the spending on agricultural goods is equal to the value of agricultural output:

$$
\frac{1}{1+\tau}\left(w_{t}\left(L_{t}-L_{t}^{A}\right)+\frac{w_{t} L_{t}^{A}}{\mu}\right)=w_{t} \frac{L_{t}^{A}}{\mu} .
$$

The following proposition expresses the growth rate as a function of exogenous variables.

PROPOSITION 5: If the growth rate is positive, the balanced growth rate is given by

$$
g=\frac{\tau \delta}{\mu+\tau}-\rho .
$$

Proof: From (38), the number of workers employed in the agricultural sector is $L_{t}^{A}=\mu L_{t} /(\tau+\mu)$. Since $g$ is the balanced growth rate, $g=\dot{n} / n$. Combination of this with (31) yields the number of individuals employed in the production of new designs: $L_{n}=g L_{t} / \delta$. Plugging the value of $r$ from (34) and the values of $L_{t}^{A}$ and $L_{n}$ into (37) yields the growth rate.

From Proposition 5, the higher the preference for manufactured goods, the higher the growth rate. This is not surprising since the manufacturing sector is the leading sector of economic development. Similar to Romer (1990), the growth rate increases with the R\&D efficiency parameter $\delta$ and decreases with the discount rate $\rho$.

\section{COMPETITION, TECHNOLOGY, AND MARKET SIZE: A DISCUSSION OF INDUSTRALIZATION IN ANCIENT CHINA AND EUROPE}

In this section, we discuss why Britain but not China became the first country to achieve industrial revolution. Scholars have quite different opinions on this issue. Our hypothesis is that achieving industrialization independently requires a delicate balance between market size and competition. From the demand side, without a large market size, adoption of increasing returns to 
scale technologies is unprofitable. From the supply side, without competition, new ideas and institutions may not be tolerated and supply of new technologies will be limited. ${ }^{20}$ From Section VII, without performing $R \& D$, the long run growth rate will be zero. Conducting $R \& D$ or not may be the crucial difference between China and Europe before 1840.

At the early stages of the Industrial Revolution, innovations depended more on experience rather than scientific knowledge (Lin, 1995). The impact of scientific knowledge on technical progress becomes more and more important during the Industrial Revolution process. While economic growth might be started by a market expansion, it was systematic R\&D investment made it possible for economic growth to be sustainable.

Geographical conditions made it difficult to unify Europe (Hicks, 1969, pp. 38-39). Competition among political powers provided a better environment for the development of scientific knowledge. ${ }^{21}$ With competition among political powers, city-states were able to exist and institutions for industrialization built up in city-states. Political competition helped experimentation, tolerance, diffusion, and preservation of technologies. Pomeranz (2000) argues that factors such as trading with the New World and use of coal earned time for Britain to defer the pressure of the land constraint. Even though competition among political powers existed long before the Industrial Revolution in Europe, after the fall of the Roman Empire, markets became local and small. The formation of nation states increased sizes of markets. With accumulation of learning of technologies from the rest of the world and systematic application of scientific knowledge to develop new technologies, Britain was able to escape the Malthus trap and achieved sustained growth.

What are the possible differences between China and Europe before the Industrial Revolution? Institutions are important for economic growth. ${ }^{22}$ One possible type of differences between ancient China and Europe may be differences in institutions. As discussed in Pomeranz (2000), it is not convincing to argue that protection of property rights in China before the Industrial Revolution was worse than that in Europe. Another type of possible differences is the degree of

\footnotetext{
${ }^{20}$ The importance of competition in affecting an industry's competitiveness is emphasized in Porter (1990) and the importance of competition in the rise of Europe is discussed in Kennedy (1989).

${ }^{21}$ Lin (1995, p. 282) argues that "in Europe, however, there were competitions between church and state, between church and church, and between state and state, which made the resistance to new basic ideas less effective."

${ }^{22}$ Impact of factor endowments on institutions and economic performance is discussed in Engerman and Sokoloff (1997). For a recent discussion of the importance of institutional heterogeneity for understanding different development, see Acemoglu et al. (2005).
} 
market integration. However, Shiue (2002) presents empirical research showing that overall effect of market integration in China was higher than previously thought. Shiue and Keller (2007) compare China and Western Europe empirically and they suggest Western Europe had no such advantages over China in its markets and extent of trade. Also market integration may be a result of technical progress since canals and railways are helpful in integrating local markets.

The differences between ancient China and England may lie in the systematic application of scientific knowledge in generating new technologies. While technical progress was fast in England during the industrialization process, it is well recognized that China lacked technological achievement in the Ming and Qing Dynasties. For example, Chao (1986, p.195) shows that among the 68 major farm implements in Chinese history, 35 were invented in the Song Dynasty (9611279), and only four were invented in the Ming Dynasty. The invention rate declined sharply after 1300 and finally came to complete halt after 1700. Mokyr (1990, Chapter 9) has a more detailed discussion of stagnation of technology in the Ming and Qing Dynasties.

One question is why China did not develop sufficient technologies? In ancient China, geographical conditions such as the existence of the North China Plain made it easier for China to unify. Unification led to larger market but lower level of tolerance of different ideas. Talented individuals were attracted to take examinations to become government officials rather than to engage in $R \& D$. Without a sufficient number of individuals engaging in $R \& D$, technical progress finally stagnated. In China's history, the Spring and Autumn period (770 B.C.-403 B. C.) and the Warring States period (403 B. C.-221 B. C.) were periods of strong cultural development. Those periods were characterized by fierce competition among political powers. It is commonly believed that the Song Dynasty was richer than other dynasties in ancient China (Lin, 1995). This may not be a coincidence. The Song dynasty was characterized by competition with two other political regimes Jin and Liao sequentially.

Other things equal, China's large size allowed it to support a large population. As a larger population may help the manufacturing sector to adopt increasing returns to scale technologies, this explains China's achievement when technologies were experience based. However, without sufficient technological improvement, growth could not be sustained. As argued in Shiue and Keller (2007), strong market performance is a necessary but not a sufficient condition for industrialization. Population growth led to short-run increase in economic activities, but sustained growth was not achieved in China before 1840 . 


\section{CONCLUSION}

This paper studies the role of population growth in the industrialization process in a general equilibrium model. We provide a formal presentation of Rostow's idea of the role of a leading sector in the process of industrialization. Population growth is a double-edged sword. Elasticity of demand for agricultural goods plays an important role in affecting whether an improvement of agricultural technology or an increase of population is beneficial to the manufacturing sector. A comparison of the development process of China and Britain before the Industrial Revolution shows that sustainable growth needs systematic R\&D investment.

There are some interesting extensions and generalizations of the model. First, fertility choice may be incorporated into the model to make the growth of population endogenous. When each family chooses the number of children to have, the growth rate of the population may not be constant over time. Because a slower growth rate may lead to two opposite effects, it is not clear ex ante whether a slower population growth rate is helpful in avoiding the subsistence constraint or not. On the one hand, the pressure on providing agricultural goods decreases. This is helpful in avoiding the subsistence constraint. On the other hand, the output of the manufacturing sector decreases. This decreases the rate of technological improvement in the agricultural sector and is harmful for avoiding the subsistence constraint. Which effect dominates depends on the values of parameters. Second, incorporating human and physical capital accumulation into the model should be useful. Finally, incorporating how political competition affects technical progress into the model may be an interesting avenue for future research.

\section{APPENDIX}

\section{Proof of Proposition 2:}

Equation (8) leads to

$$
\frac{d X_{t}^{M}}{d L_{t}}=-\frac{\partial J / \partial L_{t}}{\partial J / \partial X_{t}^{M}}
$$

Differentiation of (8) with respect to $X_{t}^{M}$ and $L_{t}$ yields

$$
\frac{\partial J}{\partial X_{t}^{M}}=(1-\mu) b^{2} \mu A_{t}^{1-\mu}\left(L_{t}-b X_{t}^{M}\right)^{\mu-2} U_{A}
$$




$$
\begin{aligned}
& \quad-b^{2} \mu^{2}\left(\frac{A_{t}}{L_{t}-b X_{t}^{M}}\right)^{1-\mu} \frac{A_{t}^{1-\mu}\left(L_{t}-b X_{t}^{M}\right)^{\mu-1}}{L_{t}} U_{A A}-\frac{U_{M M}}{L_{t}}>0, \\
& \frac{\partial J}{\partial L_{t}}=-(1-\mu) b \mu A_{t}^{1-\mu}\left(L_{t}-b X_{t}^{M}\right)^{\mu-2} U_{A} \\
& +b \mu A_{t}^{1-\mu}\left(\frac{A_{t}}{L_{t}-b X_{t}^{M}}\right)^{1-\mu}\left(\frac{\mu\left(L_{t}-b X_{t}^{M}\right)^{\mu-1}}{L_{t}}-\frac{\left(L_{t}-b X_{t}^{M}\right)^{\mu}}{L_{t}{ }^{\mu}}\right) U_{A A}+\frac{X_{t}^{M}}{L_{t}{ }^{2}} U_{M M} \\
& \leq-(1-\mu) b \mu A_{t}^{1-\mu}\left(L_{t}-b X_{t}^{M}\right)^{\mu-2} U_{A} \\
& +b \mu A_{t}^{1-\mu}\left(\frac{A_{t}}{L_{t}-b X_{t}^{M}}\right)^{1-\mu}\left(\frac{\mu\left(L_{t}-b X_{t}^{M}\right)^{\mu-1}}{L_{t}}-\frac{\left(L_{t}-b X_{t}^{M}\right)^{\mu-1}}{L_{t}}\right) U_{A A}+\frac{X_{t}^{M}}{L_{t}{ }^{2}} U_{M M} \\
& =-(1-\mu) b \mu A_{t}^{1-\mu}\left(L_{t}-b X_{t}^{M}\right)^{\mu-2}\left(U_{A}+C_{A} U_{A A}\right)+\frac{X_{t}^{M}}{L_{t}{ }^{2}} U_{M M} .
\end{aligned}
$$

A sufficient condition for $\partial J / \partial L_{t}<0$ is that $U_{A}+C_{t}^{A} U_{A A}>0$. Thus, $\varepsilon_{t}^{A}<1$ is a sufficient condition for $d X_{t}^{M} / d L_{t}>0$.

Proof of Proposition 4:

Application of Cramer's rule on (17) leads to

$$
\frac{d n_{t}}{d L_{t}}=\frac{\partial V_{1}}{\partial p_{t}^{M}}\left(\frac{\partial V_{2}}{\partial L_{t}} \frac{\partial V_{3}}{\partial L_{t}^{A}}-\frac{\partial V_{2}}{\partial L_{t}^{A}} \frac{\partial V_{3}}{\partial L_{t}}\right) / \Delta .
$$

From (18) and (20), it can be shown that

$$
\begin{aligned}
& \frac{\partial V_{2}}{\partial L_{t}^{A}} \frac{\partial V_{3}}{\partial L_{t}}-\frac{\partial V_{2}}{\partial L_{t}} \frac{\partial V_{3}}{\partial L_{t}^{A}} \\
& =\frac{\left(f^{\prime}\right)^{2}\left(L_{t}-L_{t}^{A}\right)}{\left(f^{\prime} \beta-f \beta^{\prime}\right) L_{t}{ }^{2}} U_{M M} \\
& +\mu\left(f^{\prime} \beta-f \beta^{\prime}\right) A_{t}^{1-\mu}\left(L_{t}^{A}\right)^{\mu-2}\left((\mu-1) U_{A}+\frac{\mu A_{t}^{1-\mu}\left(L_{t}^{A}\right)^{\mu} U_{A A}}{L_{t}}-\frac{\left(L_{t}^{A}\right)^{\mu+1} A^{1-\mu} U_{A A}}{L_{t}{ }^{2}}\right) \\
& \geq \frac{\left(f^{\prime}\right)^{2}\left(L_{t}-L_{t}^{A}\right)}{\left(f^{\prime} \beta-f \beta^{\prime}\right) L_{t}{ }^{2}} U_{M M}
\end{aligned}
$$




$$
\begin{aligned}
& +\mu\left(f^{\prime} \beta-f \beta^{\prime}\right) A_{t}^{1-\mu}\left(L_{t}^{A}\right)^{\mu-2}\left((\mu-1) U_{A}+\frac{\mu A_{t}^{1-\mu}\left(L_{t}^{A}\right)^{\mu} U_{A A}}{L_{t}}-\frac{\left(L_{t}^{A}\right)^{\mu} A_{t}^{1-\mu} U_{A A}}{L_{t}}\right) \\
& =\frac{\left(f^{\prime}\right)^{2}\left(L_{t}-L_{t}^{A}\right)}{\left(f^{\prime} \beta-f \beta^{\prime}\right) L_{t}{ }^{2}} U_{M M}-\mu(1-\mu)\left(f^{\prime} \beta-f \beta^{\prime}\right) A_{t}^{1-\mu}\left(L_{t}^{A}\right)^{\mu-2}\left(U_{A}+C_{t}^{A} U_{A A}\right) .
\end{aligned}
$$

If $\varepsilon_{t}^{A}<1, U_{A}+C_{t}^{A} U_{A A}>0$. This leads to $\frac{\partial V_{2}}{\partial L_{t}^{A}} \frac{\partial V_{3}}{\partial L_{t}}-\frac{\partial V_{2}}{\partial L_{t}} \frac{\partial V_{3}}{\partial L_{t}^{A}}$ and $\frac{d n_{t}}{d L_{t}}>0$.

\section{REFERENCES}

Acemoglu, Daron, Simon Johnson, and James Robinson. 2005. Institutions as the Fundamental Cause of Long-run Economic Growth, in Handbook of Economic Growth, edited by Aghion P., and S. Durlauf, Amsterdam: North-Holland.

Ashton, T. S. 1997. The Industrial Revolution 1760-1830. Oxford, UK: Oxford University Press. Chao, Kang. 1986. Man and Land in Chinese History: An Economic Analysis. Stanford University Press.

Engerman, Stanley, and Kenneth Sokoloff. 1997. Factor Endowments, Institutions, and Differential Paths of Growth Among New World Economies: A View from Economic Historians of the United States, in How Latin America fell behind, edited by Haber, S., Stanford, CA: Stanford University Press.

Durand, John. 1960. "The Population Statistics of China, A.D. 2-1953." Population Studies 13, 209-256.

Goodfriend, Marvin, and John McDermott. 1995. "Early Development." American Economic Review 85, 116-133.

Hansen, Gary, and Edward Prescott. 2002. "Malthus to Solow." American Economic Review 92, 1205-1217.

Hicks, John. 1969. A theory of economic history. Oxford, UK: Oxford University Press.

Keller, Wolfgang, and Carol Shiue. 2007. Market Integration and Economic Development: A Long-run Comparison. Review of Development Economics 11, 107-123.

Kennedy, Paul. 1989. The Rise and Fall of the Great Powers. New York: Vintage Books.

Lin, Yifu. 1995. "The Needham Puzzle: Why the Industrial Revolution did not Originate in China?" Economic Development and Cultural Change 43, 269-292. 
List, John, and Haiwen Zhou. 2007. "Internal Increasing Returns to Scale and Economic Growth." NBER working paper No. 12999.

Lucas, Robert. 1988. "On the Mechanics of Economic Development." Journal of Monetary Economics 22, 3-42.

Maddison, Angus. 1982. Phases of Capitalist Development. New York: Oxford University Press.

McEvedy, Colin, and Richard Jones. 1978. Atlas of World Population History. New York: Facts on File.

Mokyr, Joel. 1990. The Lever of Riches: Technological Creativity and Economic Progress. New York: Oxford University Press.

Murphy, Kevin, Andrei Shleifer, and Robert Vishny. 1989a. "Income Distribution, Market Size, and Industrialization." Quarterly Journal of Economics 104, 537-564.

Murphy, Kevin, Andrei Shleifer, and Robert Vishny. 1989b. "Industrialization and Big Push." Journal of Political Economy 97, 1003-1026.

Needham. Joseph. 1969. The Grand Titration: Science and Society in East and West. London, Allen and Unwin.

North, Douglass, and Robert Thomas. 1973. The Rise of the Western World. Cambridge University Press.

Pomeranz, Kenneth. 2000. The Great Divergence: China, Europe, and the Making of the Modern World Economy. Princeton, NJ: Princeton University Press.

Porter, Michael. 1990. The Comparative Advantage of Nations. New York: Free Press.

Romer, Paul. 1990. "Endogenous Technological Change." Journal of Political Economy 98, S71S102.

Rosenberg, Nathan, and Luther Birdzell, Jr. 1986. How the West Grew Rich: The Economic Transformation of the Industrial World. New York: Basic Books.

Rostow, Walt. 1960. The Stages of Economic Growth: A Non-communist Manifesto. Cambridge, UK: Cambridge University Press.

Shiue, Carol. 2002. "Transport Costs and the Geography of Arbitrage in Eighteen-century China." American Economic Review 92, 1406-1419.

Shiue, Carol. 2004. Local Granaries and Central Government Disaster Relief: Moral Hazard and Intergovernmental Finance in $18^{\text {th }}$ and $19^{\text {th }}$ Century China. Journal of Economic History 64, 101125. 
Shiue, Carol, and Wolfgang. Keller. 2007. "Markets in China and Europe on the Eve of the Industrial Revolution." American Economic Review 97, 1189-1216.

Suits, Daniel. 2005. "Agriculture." in The Structure of American Industry, $11^{\text {th }}$ edition, edited by Walter Adams and James Brock, Upper Saddle Rivers, NJ: Pearson Education.

Tamura, Robert. 1996a. "Regional Economies and Market Integration." Journal of Economic Dynamics and Control 20, 825-845.

Tamura, Robert. 1996b. "From Decay to Growth: A Demographic Transition to Economic Growth." Journal of Economic Dynamics and Control 20, 1237-1262.

Tamura, Robert. 2002. "Human Capital and the Switch from Agriculture to Industry." Journal of Economic Dynamics and Control 27, 207-242.

Tamura, Robert. 2006. "Human Capital and Economic Development." Journal of Development Economics 79, 26-72.

Zhou, Haiwen. 2004. "The Division of Labor and the Extent of the Market." Economic Theory 24, 195-209.

Zhou, Haiwen. 2007a. "Increasing Returns, the Choice of Technology, and the Gains from Trade." Southern Economic Journal 74, 581-600.

Zhou, Haiwen. 2007b. "Oligopolistic Competition and Economic Geography." Journal of Regional Science 47, 915-933.

Zhou, Haiwen. 2007c. "Factor Endowment, the Choice of Technology, and the Volume of Trade." International Economic Journal 21, 593-611. 